\title{
Mortality and cause of death in physical activity and insufficient physical activity participants: a longitudinal follow-up study using a national health screening cohort
}

Chanyang Min ${ }^{1,2+}$, Dae Myoung Yoo ${ }^{1 \dagger}$, Jee Hye Wee ${ }^{3}$,Hyo-Jeong Lee ${ }^{3}$, Soo Hwan Byun ${ }^{4}$ and Hyo Geun Choi ${ }^{1,3^{*}}$ (1)

\begin{abstract}
Background: Few studies have examined the association between physical activity (PA) and various causes of mortality in Korea. The aim of our study was to evaluate mortality and causes of death between PA and insufficient PA using Korean national cohort data.

Methods: The health screening cohort data from the Korean National Health Insurance Service-National Sample Cohort from 2009 to 2015 were used. 'PA' was determined if participants walked or performed moderate-intensity activity $\geq 5 \mathrm{~d} /$ week for $\geq 30 \mathrm{~min}$, or vigorous-intensity activity $\geq 3 \mathrm{~d} /$ week for $\geq 20 \mathrm{~min}$. Other participants were classified as 'insufficient PA'. The PA and insufficient PA groups were matched by age, sex, income, and region of residence in a 1:1 ratio. Causes of death were classified into 13 categories. Crude and adjusted hazard ratios (HRs) with 95\% confidence intervals (Cls) for all mortality rates were analyzed using a stratified Cox proportional hazard model. Age, sex, income, and region of residence were stratified. Subgroup analyses were performed according to age, sex, and obesity status. The odds ratio according to the causes of death was calculated by the chi-square test.

Results: The adjusted HR for mortality in the PA group was $0.85(95 \% \mathrm{Cl}=0.82-0.88)$. In subgroup analyses according to age, sex, and obesity status, results were consistent with the main findings in $<60$-year-old females, $\geq$ 60 -year-old males and females, and in all subgroups by obesity. The death rate by neoplasm, mental diseases, neurologic disease, circulatory disease, respiratory disease, digestive disease, abnormal finding, and trauma were lower in the PA than the insufficient PA group.

Conclusions: These results suggest that PA is inversely associated with mortality caused specifically by diseases reflected by mental, respiratory, cancer, and cardiovascular conditions. Additionally, PA is inversely associated with mortality compared to insufficient PA in all obesity status.
\end{abstract}

Keywords: Physical activity, Exercise, Mortality, Obesity, Korea

\footnotetext{
*Correspondence: pupen@naver.com

${ }^{\dagger}$ Chanyang Min and Dae Myoung Yoo contributed equally to this work.

'Hallym Data Science Laboratory, Hallym University College of Medicine, Anyang, South Korea

${ }^{3}$ Department of Otorhinolaryngology-Head \& Neck Surgery, Hallym University College of Medicine, Anyang, South Korea

Full list of author information is available at the end of the article
}

(c) The Author(s). 2020 Open Access This article is licensed under a Creative Commons Attribution 4.0 International License, which permits use, sharing, adaptation, distribution and reproduction in any medium or format, as long as you give appropriate credit to the original author(s) and the source, provide a link to the Creative Commons licence, and indicate if changes were made. The images or other third party material in this article are included in the article's Creative Commons licence, unless indicated otherwise in a credit line to the material. If material is not included in the article's Creative Commons licence and your intended use is not permitted by statutory regulation or exceeds the permitted use, you will need to obtain permission directly from the copyright holder. To view a copy of this licence, visit http://creativecommons.org/licenses/by/4.0/. The Creative Commons Public Domain Dedication waiver (http://creativecommons.org/publicdomain/zero/1.0/) applies to the data made available in this article, unless otherwise stated in a credit line to the data. 


\section{Background}

Physical activity (PA) reduces the risk of diseases, such as type 2 diabetes, cardiovascular disease, cancers, musculoskeletal disease, and depression. Moreover, physical inactivity is one of the five leading global risks for mortality [1]. In worldwide, physical inactivity is the main cause or risk factor for approximately $30 \%$ of ischemic heart disease burden, $21-25 \%$ of breast and colon cancers, and $6 \%$ of deaths [2]. Thus, PA can be one of the factors that extends lifespan. Indeed, increasing evidence has demonstrated that PA can decrease mortality, especially mortality from cardiovascular disease and cancer [3, 4]. A review study reported that PA was associated with a risk reduction of $35 \%$ (95\% confidence intervals [CIs] $=30-40)$ for mortality due to cardiovascular disease and 33\% (95\% CI $=28-37$ ) for all-cause mortality [4]. Another review study reported that high levels of PA combined with other positive lifestyle choices resulted in a $50 \%$ lower incidence of death from cardiovascular disease, and a similar outcome was found for cancer risk [3].

Likewise, several studies from Korea confirmed that PA could decrease all-cause and certain causes of death. In the Korean Metabolic Syndrome Mortality Study cohort data, exercise could decrease mortality by approximately $17-33 \%$ in various cancers, including esophageal, liver, lung, colorectal, and stomach cancers [5]. The allcause mortality was evaluated according to PAs by adjusting for age, sex, and health-related behavior factors, including smoking, alcohol intake, and nutritional risk, using Korean older adult data [6]. According to the hospital data in Korea, the mortality in Korean men was $37 \%$ lower in the regular PA group than in the nonregular PA group [7].

However, only one study has investigated the association between cause specific mortality and PA using cohort data from United State [8]. In addition, no studies have examined the mortality comparing PA and matched insufficient PA groups. The purpose of our study was to identify the mortality and causes of death between PA and insufficient PA groups according to 13 categories based on the International Classification of Diseases, 10th edition (ICD-10) using the health screening cohort from the Korean National Health Insurance Service-National Sample Cohort (NHIS-NSC) data. Mortality was compared between the PA and insufficient PA participants matched at a 1:1 ratio for age, sex, income, and region of residence.

\section{Methods}

\section{Study population and participant selection}

The ethics committee of Hallym University (HALLYM 2019-08-029) permitted the study. Institutional Review Board has waived the written consent.
The data for the health screening cohort from the Korean NHIS-NSC were used. The detail of the Korean NHIS-NSC have been described elsewhere [9, 10]. The data included 514,866 participants who randomly selected 10\% from approximately 5,150,000 health insurance holders and who had a health screening by NHIS from 2002 to 2003 in Korea. Those participants were followed up from 2002 to 2015. In 2002 to 2003, the participants were 40 to 79 years old. Among the cohort data, we excluded the participants from 2002 to 2008 because the contents for PA information were different ( $n=65,180)$. Hence, we used 449,686 participant data from 2009 to 2015.

Participants were excluded if the ID was missing ( $n=$ $1)$, the records for the health checkup date had an error $(n=1)$, or the participants did not have PA information $(n=7887)$. In total, 169,891 participants were included in the PA group, and 271,906 participants were included in the insufficient PA group. We used matching method that was used in our previous studies $[11,12]$. PA and insufficient PA groups were matched in the ratio of 1:1 by age, sex, income, and region of residence. Insufficient PA participants were sorted by random number order to minimize selection bias. The index date of each PA participant was defined as the time that the information was collected. Each insufficient PA participants were assigned the same index date as each matched PA participant. During the matching process, 2478 PA participants and 104,493 insufficient PA participants were excluded. Finally, 167,413 participants in the PA group were matched at a $1: 1$ ratio with 167,413 participants in the insufficient PA group (Fig. 1).

\section{Determination of physical activity and insufficient physical activity}

The PA information was collected using a modified International Physical Activity Questionnaire (IPAQ) [13]. We used PA information from the first record of health screening. 'PA' was defined as participants who walked $\geq 5 \mathrm{~d} /$ week for $\geq 30 \mathrm{~min}$, performed a moderateintensity activity $\geq 5 \mathrm{~d} /$ week for $30 \mathrm{~min}$, or performed a vigorous-intensity activity $\geq 3 \mathrm{~d} /$ week for $20 \mathrm{~min}$, referring to the IPAQ. Other participants were classified in the 'insufficient PA' group.

\section{Classification of causes of death}

The classification of cause specific mortality has been described elsewhere [14]. The casus of death were classified into 12 categories according to the Korean standard classification of diseases which is based on the ICD-10 codes (Additional file 1). Additionally, participants were classified as 'others' in our study if their death code was as follows: D50-D89 (diseases of the blood and bloodforming organs and certain disorders involving the 


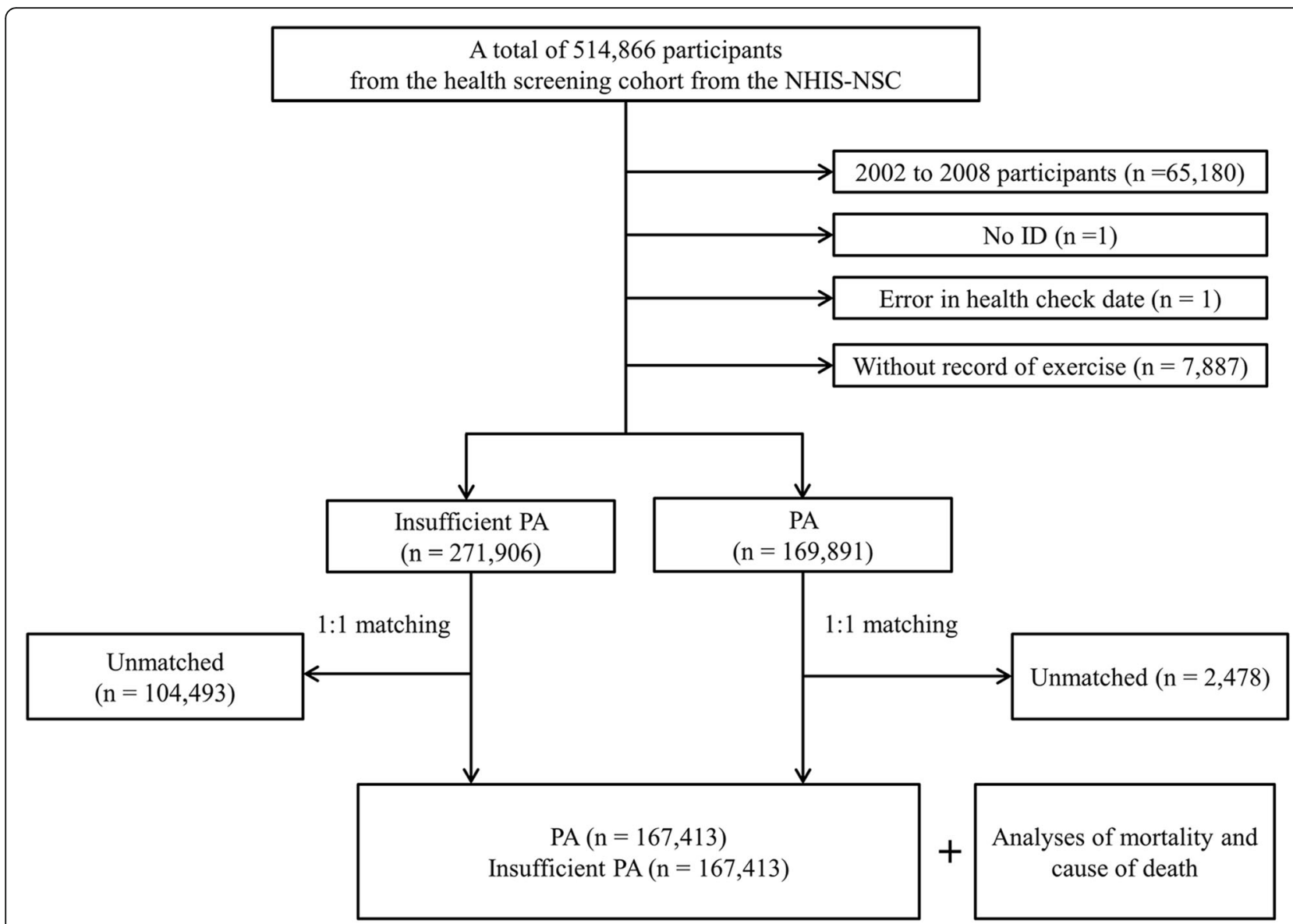

Fig. 1 A schematic illustration of the participant selection process that was used in the present study. Of a total of 514,866 participants, 167,413 of physical activity (PA) participants were matched with 167,413 insufficient PA participants for age, sex, income, and region of residence Abbreviations: NHIS-NSC, Korean National Health Insurance Service-National Sample Cohort; PA, physical activity.

immune mechanism); L00-L99 (diseases of the skin and subcutaneous tissue); Q44 or Q61 (other malformations); or missing.

\section{Covariates}

Regarding the age group category, because the data were first collected from 2002 to 2003 from individuals aged 40 to 79 years, the age of participants was $\geq 45$ years old in 2008. Therefore, age group was classified into 5-year intervals starting from 45 years old (e.g., 45-49, 50-54, $\ldots$, and $85+$ years). Income group and region of residence were categorized as our previous study [15].

Tobacco smoking, alcohol consumption, and obesity based on body mass index (BMI, $\mathrm{kg} / \mathrm{m}^{2}$ ) [16] were classified in the same way as the previous study [17].

The Charlson Comorbidity Index (CCI) contains 17 diseases to measure burden of comorbidities. The index score was given to each participant according to the severity and number of diseases. Participants were scored $1,2,3$, or 6 according to the severity of each comorbidity. If comorbidities were $\geq 2$ in one participant, then the scores were summed. Therefore, the higher scores of $\mathrm{CCI}$, the more severe and various were the comorbidities. The CCI was measured as a continuous variable ( minimum $=0$ [no comorbidity], maximum $=15$ [7 to 8 comorbidities]) $[18,19]$.

\section{Statistical analyses}

The general characteristics of study participants were presented using the chi-square test and independent $t$ test.

A comparison of the cumulative mortality in the PA and insufficient PA groups was visualized using a Kaplan-Meier survival analysis and the statistical significance was examined using the log-rank test.

A stratified Cox proportional hazard model was used to analyze the hazard ratios (HRs) with 95\% confidence intervals (CIs) for mortality in the PA group compared to those in the insufficient PA group. In this analysis, the crude and adjusted models (adjusted for obesity, smoking status, alcohol consumption, and CCI scores) 
were calculated. The analysis was stratified by age, sex, income, and region of residence.

For the subgroup analyses, we re-grouped participants by age and sex ( $<60$ years old and $\geq 60$ years old; males and females) and analyzed the crude and adjusted models with a stratified Cox model.

Additionally, subgroup analyses according to obesity (underweight, normal weight, overweight, obese I, and obese II) were performed using crude and adjusted models (adjusted for age, sex, income, region of residence, smoking status, alcohol consumption, and CCI scores). In these analyses, we used an unstratified Cox model.

Death rates according to cause specific mortality were calculated using the chi-square test. The false discovery rate was used to adjust for incorrect rejections of the null hypothesis. The odds ratios (ORs) with 95\% CIs for all-cause mortality and each cause of mortality were calculated using the chi-square test.

Significance for a two-sided test was determined with a $P$-value $<0.05$. For statistical analyses, we used SAS version 9.4 (SAS Institute Inc., Cary, NC, USA).

\section{Results}

The mean follow-up period for the PA group was 65.18 months (standard deviation $[\mathrm{SD}]=15.69$ months) and for insufficient PA group was 64.92 months $(\mathrm{SD}=16.05$ months).

The rate of death was significantly lower in the PA group $(5483 / 167,413$ [3.3\%]) than in the insufficient PA group $(6781 / 167,413$ [4.1\%], $P<0.001$, Table 1$)$. The cumulative survival rate was lower (log-rank test, $P<$ 0.001) in the insufficient PA group than in the PA group in the Kaplan-Meier survival analysis (Fig. 2).

The adjusted HR for mortality in the PA group was significantly lower than the insufficient PA group (0.85, $95 \% \mathrm{CI}=0.82-0.88, P<0.001)$. In subgroup analyses among age and sex subgroups, the results were consistent with the above findings in $<60$ years old female group and $\geq 60$ years old male and female groups $(P<0.05$, Table 2).

Subgroup analyses according to obesity were performed. The adjusted HRs for mortality were lower in the PA group than in the insufficient PA group in all obesity subgroups $(P<0.01$, Table 3$)$.

The OR for all-cause mortality was $0.80(95 \% \mathrm{CI}=$ $0.77-0.83, P<0.001)$ in the PA group. Mortality caused by a neoplasm, mental disease, neurologic disease, circulatory disease, respiratory disease, digestive disease, abnormal finding, and trauma was lower in the PA group than the insufficient PA group $(P<0.05)$. The OR for mortality was the lowest for mental disease $(0.47,95 \%$ $\mathrm{CI}=0.31-0.70, P=0.001)$ in the PA group. Mortality caused by infection, metabolic disease, muscular disease, and genitourinary disease was not statistically significant between the PA and insufficient PA groups (Table 4). Specific causes of death rates are presented in the Additional file 2.

\section{Discussion}

We confirmed the association of mortality by matching PA and insufficient PA participants at a 1:1 ratio by age, sex, income, and region of residence using Korean national cohort data. In addition, we investigated various causes of death, including cancer (neoplasm), circulatory disease, mental disease, and respiratory disease compared between the PA and insufficient PA groups. We found that the all-cause mortality in the PA group was lower than in the insufficient PA group, specifically in female of all age groups, in older male group, and in all obesity groups. Among the causes of death, mental disease had the lowest mortality in the PA group compared with the insufficient PA group. In addition, respiratory disease, neurologic disease, circulatory disease, digestive disease, abnormal finding, trauma, and neoplasm (cancer) mortalities were also lower in the PA group than the insufficient PA group.

In our study, due to the lack of information from secondary data, PA information was not specifically collected according to the length of time of each intensity of PA. Although we grouped participants into the PA group based on the broad definition refer to the IPAQ criteria [13], the PA group was associated with a lower risk of mortality than with the insufficient PA group. A review study has suggested that a large amount of PA exceeding the recommended amount of PA is better to lower the mortality risk [20]. Conversely, one study demonstrated that light-intensity PA ( 3 to $<9$ metabolic equivalents [METs] hours/week) in older adults (aged 50 to 74 years) may be associated with a lower risk of mortality than with little/no light-intensity PA. Moreover, the study reported that all-cause mortality was not significantly different between light PA and other higher intensity PAs [21]. Therefore, the findings from the above studies can explain the simplification of the PA group in our study. We additionally performed subgroup analyses according to the types of PA performed by the participants (walking, moderate-intensity activity, vigorousintensity activity, and other combinations of PAs) with each matched insufficient PA participant. As suggested in previous studies, the risk of all-cause mortality was lower even in the participants who performed walking, a simpler and lighter PA than other types of PA (Additional file 3).

In our study, all-cause mortality including mortality due to circulatory disease (cardiovascular disease) and neoplasm (cancer), was lower in PA group compared with the insufficient PA group. Previous studies reported 
Table 1 General Characteristics of Participants

\begin{tabular}{|c|c|c|c|}
\hline \multirow[t]{2}{*}{ Characteristics } & \multicolumn{3}{|c|}{ Total participants } \\
\hline & $\mathrm{PA}$ & Insufficient PA & $P$-value \\
\hline Age (years old, n, \%) & & & 1.000 \\
\hline $45-49$ & $17,218(10.3)$ & $17,218(10.3)$ & \\
\hline $50-54$ & $42,312(25.3)$ & $42,312(25.3)$ & \\
\hline $55-59$ & $29,828(17.8)$ & $29,828(17.8)$ & \\
\hline $60-64$ & $31,678(18.9)$ & $31,678(18.9)$ & \\
\hline $65-69$ & $18,687(11.2)$ & $18,687(11.2)$ & \\
\hline $70-74$ & $18,377(11.0)$ & $18,377(11.0)$ & \\
\hline $75-79$ & $6289(3.8)$ & $6289(3.8)$ & \\
\hline $80-84$ & $2664(1.6)$ & $2664(1.6)$ & \\
\hline $85+$ & $360(0.2)$ & $360(0.2)$ & \\
\hline $\operatorname{Sex}(n, \%)$ & & & 1.000 \\
\hline Male & $93,645(55.9)$ & $93,645(55.9)$ & \\
\hline Female & $73,768(44.1)$ & $73,768(44.1)$ & \\
\hline Income (n, \%) & & & 1.000 \\
\hline 1 (lowest) & $24,270(14.5)$ & $24,270(14.5)$ & \\
\hline 2 & $21,864(13.1)$ & $21,864(13.1)$ & \\
\hline 3 & $25,462(15.2)$ & $25,462(15.2)$ & \\
\hline 4 & $34,622(20.7)$ & $34,622(20.7)$ & \\
\hline 5 (highest) & $61,195(36.6)$ & $61,195(36.6)$ & \\
\hline Region of residence $(n, \%)$ & & & 1.000 \\
\hline Urban & $79,044(47.2)$ & $79,044(47.2)$ & \\
\hline Rural & $88,369(52.8)$ & $88,369(52.8)$ & \\
\hline Obesity $(n, \%) \neq$ & & & $<0.001^{*}$ \\
\hline Underweight & $3331(2.0)$ & $3778(2.3)$ & \\
\hline Normal & $58,361(34.9)$ & $58,312(34.8)$ & \\
\hline Overweight & $48,046(28.7)$ & $46,304(27.7)$ & \\
\hline Obese I & $53,294(31.8)$ & $54,000(32.3)$ & \\
\hline Obese II & $4381(2.6)$ & $5019(3.0)$ & \\
\hline Smoking status (n, \%) & & & $<0.001^{*}$ \\
\hline Nonsmoker & $105,936(63.3)$ & $115,095(68.8)$ & \\
\hline Past smoker & $34,938(20.9)$ & $21,688(13.0)$ & \\
\hline Current smoker & $26,539(15.9)$ & $30,630(18.3)$ & \\
\hline Alcohol consumption & & & $<0.001^{*}$ \\
\hline$<1$ time a week & $96,476(57.6)$ & $112,334(67.1)$ & \\
\hline$\geq 1$ time a week & $70,937(42.4)$ & $55,079(32.9)$ & \\
\hline $\mathrm{CCl}$ score (mean, SD) & $0.58(1.29)$ & $0.62(1.32)$ & $<0.001+$ \\
\hline Death & $5483(3.3)$ & $6781(4.1)$ & $<0.001^{*}$ \\
\hline Age $<60$ years old, males & $853(1.7)$ & $841(1.7)$ & 0.769 \\
\hline Age $<60$ years old, females & $232(0.6)$ & $266(0.7)$ & 0.126 \\
\hline Age $\geq 60$ years old, males & $3296(7.7)$ & $4165(9.7)$ & $<0.001^{*}$ \\
\hline Age $\geq 60$ years old, females & $1102(3.1)$ & $1509(4.3)$ & $<0.001^{*}$ \\
\hline
\end{tabular}

Abbreviations: $\mathrm{CCl}$ Charlson comorbidity index, PA physical activity

* Chi-square test. Significance at $P<0.05$

+ Independent $t$ test. Significance at $P<0.05$

₹ Obesity (BMI, body mass index, $\mathrm{kg} / \mathrm{m}^{2}$ ) was categorized as $<18.5$ (underweight), $\geq 18.5$ to $<23$ (normal), $\geq 23$ to $<25$ (overweight), $\geq 25$ to $<30$ (obese I), and $\geq 30$ (obese II) 


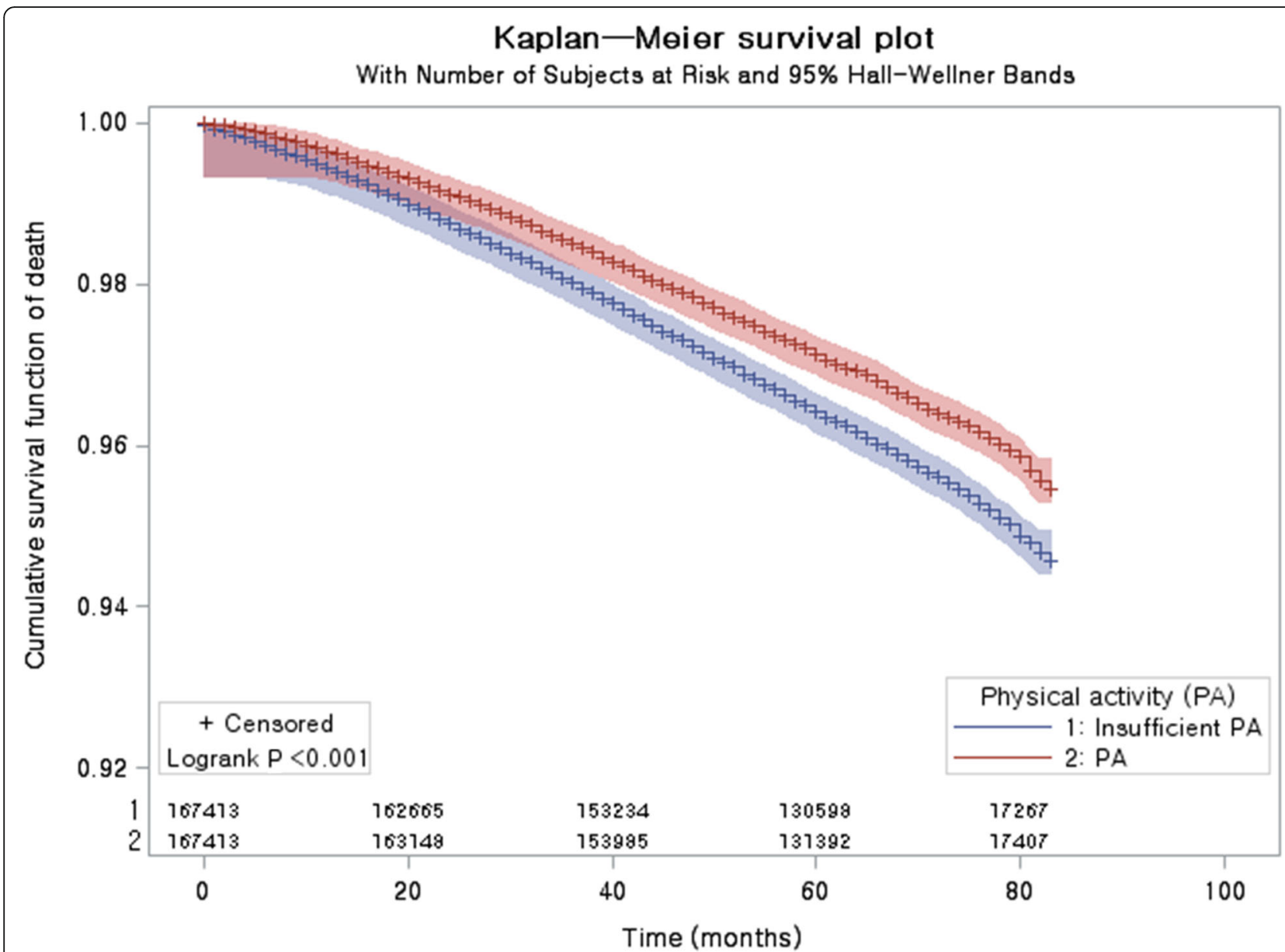

Fig. 2 Kaplan-Meier survival analysis and the log-rank test. The cumulative survival rate was lower in the insufficient physical activity (PA) group than in the PA groupAbbreviations: PA, physical activity.

similar results to our study findings [3-5]. Although the mechanisms between PA and mortality are not fully understood, various benefits of PA that are important predictors of chronic disease such as cardiovascular disease and cancer have been suggested as a link between PA and decreasing mortality. Some related benefits of PA are as follows: changing body composition, antiinflammatory effects, decreasing biological and psychosocial stressors that optimize neurogenesis, and an improved immune system [22-24].

Mortality due to mental disease, including Alzheimer's disease and dementia, was the lowest among the causes of mortality in the PA group than the insufficient PA group in our study. The results from previous studies are consistent with our study findings. One study found that mortality was lower in the higher intensity PA groups $(\geq 150 \mathrm{~min} /$ week for each non-recreational and recreational PA) than the lower intensity PA group (< $150 \mathrm{~min} /$ week for each of non-recreational and recreational PA) in Korean Alzheimer's disease patients (HR = $0.22,95 \% \mathrm{CI}=0.05-0.88, P=0.033$ ) [25]. Another study has also reported that improving mental health increases PA [26]. Brain blood flow increases via PA could lead to changes in brain metabolism and increases in neural activation, thus decreasing the onset of dementia [27]. Hence, PA could prevent or improve mental disease and thus may decrease mental disease mortality.

The mortality associated with respiratory diseases, specifically influenza, pneumonia, and chronic lower respiratory diseases, was also lower in the PA group than the insufficient PA group in our study. One study reported that walking $\geq 2$ $\mathrm{h} /$ week was associated with a lower respiratory disease mortality [28]. Another study demonstrated that higher amounts of walking or running were associated with a lower risk of respiratory disease mortality [29]. Previous studies suggest that PA could enhance the immune system by increasing anti-influenza IgG and IgM levels or could inhibit lung inflammation by reducing inflammatory cytokines and oxidative stress markers [30,31]. Based on previous studies and our study result, PA, specifically aerobic PA such as walking, could lower the risk of respiratory disease mortality by enhancing the immune system. 
Table 2 Crude and adjusted hazard ratios (95\% confidence interval) for mortality in the physical activity (PA) group compared with the insufficient PA group with subgroup analyses according to age and sex

\begin{tabular}{|c|c|c|c|c|}
\hline \multirow[t]{2}{*}{ Characteristics } & \multicolumn{4}{|l|}{ Hazard ratios } \\
\hline & Crudet & $P$-value & Adjusted†‡ & $P$-value \\
\hline \multicolumn{5}{|c|}{ Total participants $(n=334,826)$} \\
\hline PA & $0.79(0.77-0.82)$ & $<0.001^{*}$ & $0.85(0.82-0.88)$ & $<0.001^{*}$ \\
\hline Insufficient PA & 1.00 & & 1.00 & \\
\hline \multicolumn{5}{|c|}{ Age $<60$ years old, males $(n=101,708)$} \\
\hline PA & $1.01(0.92-1.12)$ & 0.772 & $1.05(0.95-1.16)$ & 0.323 \\
\hline Insufficient PA & 1.00 & & 1.00 & \\
\hline \multicolumn{5}{|c|}{ Age $<60$ years old, females $(n=77,008)$} \\
\hline PA & $0.87(0.73-1.04)$ & 0.127 & $0.81(0.67-0.96)$ & $0.018^{*}$ \\
\hline Insufficient PA & 1.00 & & 1.00 & \\
\hline \multicolumn{5}{|c|}{ Age $\geq 60$ years old, males $(n=85,582)$} \\
\hline PA & $0.77(0.74-0.81)$ & $<0.001^{*}$ & $0.84(0.80-0.88)$ & $<0.001^{*}$ \\
\hline Insufficient PA & 1.00 & & 1.00 & \\
\hline \multicolumn{5}{|c|}{ Age $\geq 60$ years old, females $(n=70,528)$} \\
\hline PA & $0.72(0.66-0.78)$ & $<0.001^{*}$ & $0.78(0.72-0.84)$ & $<0.001^{*}$ \\
\hline Insufficient PA & 1.00 & & 1.00 & \\
\hline
\end{tabular}

Abbreviations: $\mathrm{CCl}$ Charlson comorbidity index, PA physical activity

* Stratified Cox-proportional hazard regression model, significance at $P<0.05$

† Models stratified by age, sex, income, and region of residence

₹ A model adjusted for obesity, smoking, alcohol consumption, and CCI scores

Since most of retirement ages in Korea are 60 years old, we classified the age group as $<60$ years and $\geq 60$ years old in our study. The risk of mortality was not significant between the PA and insufficient PA groups in males $<60$ years old. Conversely, the risk of mortality was significantly lower in the PA group than the insufficient PA group in females $<60$ years old. The reason for the inconsistent findings according to sex may be because our study data did not specifically classify occupational PA and leisure time PA in the PA questionnaire. A previous study defined high occupational PA as individuals who were taking stairs $>20$ floors or walking $>3$ $\mathrm{km} /$ day at work, often taking stairs and carrying light stuffs, or exerting a lot of physical effort and frequently carrying heavy stuffs. The study reported that, unlike leisure-time PA, the risk of all-cause mortality and cardiovascular disease mortality was higher in males with a high occupational PA, while no difference was shown among the intensity of occupational PAs in females [32]. The cause of different findings between males and females would be longer and higher intensity work in males than females [33, 34]. Moreover, exceeding the recommended times and intensity of PA, such as over 8 $\mathrm{h}$ of high-intensity work, may impair cardiovascular health [35]. Therefore, this so-called PA health paradox
Table 3 Subgroup analyses of crude and adjusted hazard ratios (95\% confidence interval) for mortality in the physical activity (PA) group compared with the insufficient PA group according to obesity

\begin{tabular}{lllll}
\hline Characteristics & Hazard ratios & & & \\
\cline { 2 - 5 } & Crude & $P$-value & Adjustedt & $P$-value \\
\hline Underweight $(n=7109)$ & $0.77(0.67-0.88)$ & $<0.001^{*}$ & $0.83(0.72-0.95)$ & $0.008^{*}$ \\
PA & & 1.00 & \\
Insufficient PA & 1.00 & & \\
Normal weight $(n=116,673)$ & & & \\
PA & $0.81(0.77-0.86)$ & $<0.001^{*}$ & $0.85(0.81-0.90)$ & $<0.001^{*}$ \\
Insufficient PA & 1.00 & 1.00 & \\
Overweight $(n=94,350)$ & & & \\
PA & $0.85(0.79-0.91)$ & $<0.001^{*}$ & $0.90(0.84-0.97)$ & $0.005^{*}$ \\
Insufficient PA & 1.00 & & 1.00 & \\
Obese I ( $n=107,294)$ & & & \\
PA & $0.80(0.75-0.86)$ & $<0.001^{*}$ & $0.80(0.75-0.86)$ & $<0.001^{*}$ \\
Insufficient PA & 1.00 & & 1.00 & \\
Obese II $(n=9400)$ & & & $0.007^{*}$ \\
PA & $0.63(0.50-0.79)$ & $<0.001^{*}$ & $0.72(0.57-0.92)$ & \\
Insufficient PA & 1.00 & & 1.00 & \\
\hline Ab & & &
\end{tabular}

Abbreviations: $\mathrm{CCl}$ Charlson comorbidity index, $P A$ physical activity * Unstratified Cox-proportional hazard regression model, significance at $P<0.05$

† A model adjusted for age, sex, income, region of residence, smoking, alcohol consumption, and $\mathrm{CCl}$ scores

$[36,37]$ may affect the different study findings between males and females.

In all obesity categories, including underweight, the HRs for mortality were lower in the PA group than the insufficient PA group in our study. The evidence demonstrated that BMI has a U-shaped or J-shaped association with higher mortality not only in overweight or obesity, but also in underweight [38]. Although we could not find a study that investigated the association between underweight individuals with physical activity and mortality, the findings from a previous study show that the log hazard of death was higher in sedentary men with lower BMI percentiles than in active men with lower BMI percentiles [39]. Therefore, underweight individuals could improve their health by improving physical activity. Further studies should elucidate the association between PA and mortality in underweight individuals.

The main strength of our study was using large cohort data over a 7-year follow-up period. Moreover, we matched participants in the PA and insufficient PA groups at a 1:1 ratio by age, sex, income, and region of residence to independently compare the causes of mortality. In addition, we conducted subgroup analyses according to obesity status to identify whether PA with all obesity status are negatively associated with mortality. 
Table 4 The difference in mortality between the physical activity (PA) and insufficient PA groups according to cause of death

\begin{tabular}{|c|c|c|c|c|}
\hline \multirow[t]{2}{*}{ Cause of death } & \multicolumn{4}{|l|}{ Total participants } \\
\hline & $\mathrm{PA}(n=167,413)$ & Insufficient PA $(n=167,413)$ & Odds ratio $(95 \% \mathrm{Cl})$ & $P$-value \\
\hline All-cause death $(n, \%)$ & $5483(100.0)$ & $6781(100.0)$ & $0.80(0.77-0.83)$ & $<0.001^{*}$ \\
\hline Infection $(n, \%)$ & $110(2.0)$ & $142(2.1)$ & $0.78(0.60-0.99)$ & 0.057 \\
\hline Neoplasm (n,\%) & $2425(44.2)$ & $2781(41.0)$ & $0.87(0.82-0.92)$ & $<0.001^{*}$ \\
\hline Metabolic disease $(n, \%)$ & $165(3.0)$ & $202(3.0)$ & $0.82(0.67-1.00)$ & 0.063 \\
\hline Mental disease $(n, \%)$ & $33(0.6)$ & $71(1.1)$ & $0.47(0.31-0.70)$ & $0.001^{*}$ \\
\hline Neurologic disease $(n, \%)$ & $110(2.0)$ & $155(2.3)$ & $0.71(0.56-0.91)$ & $0.010^{*}$ \\
\hline Circulatory disease $(n, \%)$ & $1011(18.4)$ & $1311(19.3)$ & $0.77(0.71-0.84)$ & $<0.001^{*}$ \\
\hline Respiratory disease $(n, \%)$ & $372(6.8)$ & $567(8.4)$ & $0.66(0.58-0.75)$ & $<0.001^{*}$ \\
\hline Digestive disease $(n, \%)$ & $171(3.1)$ & $215(3.2)$ & $0.80(0.65-0.97)$ & $0.036^{*}$ \\
\hline Muscular disease $(n, \%)$ & $30(0.6)$ & $35(0.5)$ & $0.86(0.53-1.40)$ & 0.535 \\
\hline Genitourinary disease $(n, \%)$ & $79(1.4)$ & $87(1.3)$ & $0.91(0.67-1.23)$ & 0.535 \\
\hline Abnormal finding $(n, \%)$ & $283(5.2)$ & $365(5.4)$ & $0.78(0.66-0.91)$ & $0.002^{*}$ \\
\hline Trauma $(n, \%)$ & $669(12.2)$ & $801(11.8)$ & $0.84(0.75-0.93)$ & $0.002^{*}$ \\
\hline Others $(n, \%)$ & $25(0.5)$ & $49(0.7)$ & $0.51(0.32-0.83)$ & $0.009^{*}$ \\
\hline
\end{tabular}

Abbreviation: $P A$ physical activity

* Chi-square test. Significance at false discovery rate-adjusted $P<0.05$

Furthermore, we investigated various causes of mortality between the PA and insufficient PA groups.

Several limitations of our study should be considered. First, due to the use of secondary data, we could not calculate the METs in our study. Therefore, we could not classify the PA group into specific categories. Moreover, we could not follow-up whether the PA status was maintained until the end of the follow-up period because it was not mandatory for the participants to have a health screening every year. In addition, PA was not specifically classified according to whether it was performed during leisure or occupational time. Due to the use of secondary data, only participants aged $\geq 45$ years were included. Regarding BMI, obesity status may not be correct because BMI records were replaced with the mean BMI from the total selected participants for 115 participants with missing BMI records [40]. Moreover, to preserve the number of participants, we were unable to perform a subgroup analysis based on obesity status using the stratified model because the participants in the PA and insufficient PA groups did not match according to their obesity status. Because we performed an observational study, definite causality between PA and mortality could not be determined.

\section{Conclusion}

The results suggest that PA is negatively associated with mortality, including mortality from not only cancer or cardiovascular disease, but also diseases such as mental disease or respiratory disease. In addition, PA is negatively associated with mortality compared with insufficient PA for all of obesity status.

\section{Supplementary information}

Supplementary information accompanies this paper at https://doi.org/10. 1186/s12889-020-09564-X.

Additional file 1:. Supplementary file 1. Korean standard classification of diseases based on the ICD-10 codes

Additional file 2:. S1Table. Cause of death in the physical activity (PA) and insufficient PA groups

Additional file 3:. S2 Table. Subgroup analyses of crude and adjusted hazard ratios (95\% confidence interval) for mortality in the physical activity (PA) group compared with the insufficient PA group according to types of exercise

\section{Abbreviations}

CCl: Charlson Comorbidity Index; Cls: Confidence intervals; HRs: Hazard ratios; HURF: Hallym University Research Fund; ICD-10: International Classification of Diseases, 10th edition; IPAQ: International Physical Activity Questionnaire; METs: Metabolic equivalents; NHIS: National Health Insurance Service; NHIS-NSC: National Health Insurance Service-National Sample Cohort; NHISS: Korean National Health Insurance Sharing Service; NRF: National Research Foundation; ORs: Odds ratios; PA: Physical activity; SD: Standard deviation

\section{Acknowledgments}

The manuscript was edited for proper English language, grammar, punctuation, spelling, and overall style by the highly qualified native Englishspeaking editors at American Journal Experts (B805-FB1B-5ADB-FBB1-234P).

\section{Authors' contributions}

CM and DMY contributed equally to this work. They were major contributors to writing the manuscript. JHW and HJL analyzed and interpreted the data. SHB visualized the findings as figures and tables. HGC conceptualized the study design and was the major contributor to reviewing and revising the manuscript. All authors read and approved the final manuscript.

\section{Funding}

This work was supported by the Hallym University Research Fund (HURF) and in part by research grants (NRF-2018-R1D1A1A02085328 and NRF2019R1A6A3A01091963) from the National Research Foundation (NRF) of Korea. The funding bodies contributed to the data analysis fee and the labor 
costs of researchers. The funding bodies have no role in the design of the study and collection, analysis, interpretation of the data, or in writing the manuscript.

\section{Availability of data and materials}

The data that support the findings of this study are available from the NHISS and all researchers can apply for using the database to conduct their studies. Permission from the NHIS is required to access the database. However, restrictions apply to the availability of these data due to ethical concerns, which were used under license for the current study and so are not publicly available. Any raw data are not allowed to be brought out due to the ethical concerns.

\section{Ethics approval and consent to participate}

This study used anonymized secondary data from the Korean National Health Insurance Sharing Service (NHISS). The Korean National Health Insurance Service (NHIS) permitted to access the raw data of the health screening cohort from the NHIS-NSC (NHIS-2019-2-287). The Ethics Committee of Hallym University approved this study (HALLYM 2019-08-029). Written informed consent was waived by the Institutional Review Board.

\section{Consent for publication}

Not Applicable.

\section{Competing interests}

The authors declare that they have no competing interests.

\section{Author details}

${ }^{1}$ Hallym Data Science Laboratory, Hallym University College of Medicine, Anyang, South Korea. ${ }^{2}$ Graduate School of Public Health, Seoul National University, Seoul, South Korea. ${ }^{3}$ Department of Otorhinolaryngology-Head \& Neck Surgery, Hallym University College of Medicine, Anyang, South Korea. ${ }^{4}$ Department of Oral \& Maxillofacial Surgery, Dentistry, Sacred Heart Hospital, Hallym University College of Medicine, Anyang, South Korea.

Received: 21 May 2020 Accepted: 17 September 2020

Published online: 29 September 2020

\section{References}

1. World Health Organization (WHO). Global Health Risks: Mortality and burden of disease attributable to selected major risks. Geneva: World Health Organization. https://www.who.int/healthinfo/global_burden_disease/ GlobalHealthRisks_report_full.pdf (2009) accessed 7 May 2020

2. World Health Organization (WHO). Global Strategy on Diet, Physical Activity and Health. WHO. https://www.who.int/dietphysicalactivity/pa/en/ (2020) accessed 8 May 2020.

3. Lacombe J, Armstrong MEG, Wright FL, Foster C. The impact of physical activity and an additional behavioural risk factor on cardiovascular disease, cancer and all-cause mortality: a systematic review. BMC Public Health. 2019:19(1):900

4. Nocon M, Hiemann T, Muller-Riemenschneider F, Thalau F, Roll S, Willich SN Association of physical activity with all-cause and cardiovascular mortality: a systematic review and meta-analysis. Eur J Cardiovasc Prev Rehabil. 2008; 15(3):239-46.

5. Jee $Y$, Kim $Y$, Jee $S H$, Ryu M. Exercise and cancer mortality in Korean men and women: a prospective cohort study. BMC Public Health. 2018;18(1):761.

6. Cho J, Lee I, Park S, Jin Y, Kim D, Kim S, et al. Physical activity and all-cause mortality in Korean older adults. Ann Hum Biol. 2018;45(4):337-45.

7. Park M-S, Chung S-Y, Chang Y, Kim K. Physical activity and physical fitness as predictors of all-cause mortality in Korean men. J Korean Med Sci. 2009; 24(1):13-9.

8. Zhao M, Veeranki SP, Magnussen CG, Xi B. Recommended physical activity and all cause and cause specific mortality in US adults: prospective cohort study. BMJ. 2020:370:m2031.

9. Kim SY, Min C, Oh DJ, Choi HG. Tobacco smoking and alcohol consumption are related to benign parotid tumor: a nested casecontrol study using a National Health Screening Cohort. Clin Exp Otorhinolaryngol. 2019;12(4):412-9.

10. Lee J, Lee JS, Park SH, Shin SA, Kim K. Cohort profile: the National Health Insurance Service-National Sample Cohort (NHIS-NSC). South Korea Int J Epidemiol. 2017;46(2):e15
11. Byun SH, Min C, Kim YB, Kim H, Kang SH, Park BJ, et al. Analysis of chronic periodontitis in tonsillectomy patients: a longitudinal follow-up study using a National Health Screening Cohort. Appl Sci. 2020;10(10):3663.

12. Min C, Lim H, Lim JS, Sim S, Choi HG. Increased risk of migraine in patients with psoriasis: a longitudinal follow up study using a national sample cohort. Medicine (Baltimore). 2019;98(17):e15370.

13. International Physical Activity Questionnaire. International Physical Activity Questionnaire (IPAQ) scoring protocol. https://sites.google.com/site/theipaq/ scoring-protocol (2019) accessed 27 March 2020.

14. Choi HG, Lim JS, Lee YK, Sim S, Kim M. Mortality and cause of death in south Korean patients with Parkinson's disease: a longitudinal follow-up study using a national sample cohort. BMJ Open. 2019;9(9):e029776.

15. Kim SY, Min C, Oh DJ, Choi HG. Bidirectional Association Between GERD and Asthma: Two Longitudinal Follow-Up Studies Using a National Sample Cohort. J Allergy Clin Immunol Pract. 2020:8(3):1005-1013.e1009.

16. World Health Organization. The Asia-Pacific perspective: redefining obesity and its treatment. Sydney: Health Communications Australia; 2000.

17. Kim SY, Oh DJ, Park B, Choi HG. Bell's palsy and obesity, alcoho consumption and smoking: a nested case-control study using a national health screening cohort. Sci Rep. 2020;10(1):4248.

18. Quan H, Li B, Couris CM, Fushimi K, Graham P, Hider P, et al. Updating and validating the Charlson comorbidity index and score for risk adjustment in hospital discharge abstracts using data from 6 countries. Am J Epidemiol. 2011;173(6):676-82.

19. Quan H, Sundararajan V, Halfon P, Fong A, Burnand B, Luthi JC, et al. Coding algorithms for defining comorbidities in ICD-9-CM and ICD-10 administrative data. Med Care. 2005:43(11):1130-9.

20. Blond K, Brinklov CF, Ried-Larsen M, Crippa A, Grontved A. Association of high amounts of physical activity with mortality risk: a systematic review and meta-analysis. Br J Sports Med. 2019:bjsports-2018-100393.

21. Rees-Punia E, Deubler E, Campbell P, Gapstur SM, Patel A. Light-intensity physical activity in a large prospective cohort of older US adults: a 21-year follow-up of mortality. Gerontology. 2020;66(3):259-65.

22. Idorn M, Thor SP. Exercise and cancer: from "healthy" to "therapeutic"? Cancer Immunol Immunother. 2017;66(5):667-71.

23. Silverman MN, Deuster PA. Biological mechanisms underlying the role of physical fitness in health and resilience. Interface Focus. 2014;4(5):20140040.

24. Timmons BW, Cieslak T. Human natural killer cell subsets and acute exercise: a brief review. Exerc Immunol Rev. 2008;14:8-23.

25. Minn YK, Choi SH, Suh YJ, Jeong JH, Kim EJ, Kim JH, et al. Effect of physical activity on the progression of Alzheimer's disease: the clinical research Center for Dementia of South Korea study. J Alzheimers Dis. 2018;66(1):249-61.

26. Jun ER, Kim SH, Cho YJ, Kim YA, Lee JY. The influence of negative mental health on the health behavior and the mortality risk: analysis of Korean longitudinal study of aging from 2006 to 2014. Korean J Fam Med. 2019;40(5):297-306.

27. Barnes JN. Exercise, cognitive function, and aging. Adv Physiol Educ. 2015 39(2):55-62.

28. Patel AV, Hildebrand JS, Leach CR, Campbell PT, Doyle C, Shuval K, et al. Walking in relation to mortality in a large prospective cohort of older U.S. adults. Am J Prev Med. 2018;54(1):10-9.

29. Williams PT. Dose-response relationship between exercise and respiratory disease mortality. Med Sci Sports Exerc. 2014;46(4):711-7.

30. Kohut ML, Cooper MM, Nickolaus MS, Russell DR, Cunnick JE. Exercise and psychosocial factors modulate immunity to influenza vaccine in elderly individuals. J Gerontol A Biol Sci Med Sci. 2002:57(9):M557-62.

31. Rigonato-Oliveira NC, Mackenzie B, Bachi ALL, Oliveira-Junior MC, Santos-Dias A, Brandao-Rangel MAR, et al. Aerobic exercise inhibits acute lung injury: from mouse to human evidence exercise reduced lung injury markers in mouse and in cells. Exerc Immunol Rev. 2018;24: $36-44$.

32. Wanner M, Lohse T, Braun J, Cabaset S, Bopp M, Krause N, et al. Occupational physical activity and all-cause and cardiovascular disease mortality: results from two longitudinal studies in Switzerland. Am J Ind Med. 2019;62(7):559-67.

33. Messing K. Physical exposures in work commonly done by women. Can J Appl Physiol. 2004;29(5):639-56.

34. Messing K, Dumais L, Courville J, Seifert AM, Boucher M. Evaluation of exposure data from men and women with the same job title. J Occup Med. 1994;36(8):913-7.

35. Jorgensen K. Permissible loads based on energy expenditure measurements. Ergonomics. 1985;28(1):365-9. 
36. Holtermann A, Hansen JV, Burr H, Sogaard K, Sjogaard G. The health paradox of occupational and leisure-time physical activity. Br J Sports Med. 2012;46(4):291-5.

37. Holtermann A, Krause N, van der Beek AJ, Straker L. The physical activity paradox: six reasons why occupational physical activity (OPA) does not confer the cardiovascular health benefits that leisure time physical activity does. Br J Sports Med. 2018;52(3):149-50.

38. World Health Organization (WHO). Obesity-Preventing and managing the global epidemic. Report of a WHO consultation on Obesity. Geneva: WHO; 1999. p. 2000.

39. Heitmann BL, Hills AP, Frederiksen P, Ward LC. Obesity, leanness, and mortality: effect modification by physical activity in men and women. Obesity (Silver Spring). 2009;17(1):136-42.

40. Kang $\mathrm{H}$. The prevention and handling of the missing data. Korean J Anesthesiol. 2013;64(5):402-6.

\section{Publisher's Note}

Springer Nature remains neutral with regard to jurisdictional claims in published maps and institutional affiliations.

Ready to submit your research? Choose BMC and benefit from:

- fast, convenient online submission

- thorough peer review by experienced researchers in your field

- rapid publication on acceptance

- support for research data, including large and complex data types

- gold Open Access which fosters wider collaboration and increased citations

- maximum visibility for your research: over $100 \mathrm{M}$ website views per year

At BMC, research is always in progress.

Learn more biomedcentral.com/submissions 